\title{
Trace Elements in Young Field Hockey Players and Fencers
}

\author{
Rylova NV1,2*, Zholinsky AV² and Sereda $\mathrm{AP}^{2}$ \\ ${ }^{1}$ Federal Scientific Clinical Center for Sport Medicine and Rehabilitation, Russia \\ 2State Medical University, Russia
}

*Corresponding author: Rylova NV, State Medical University, 49 Butlerova str, Kazan, 420012, Russia Tel: +7(917)3373393; Email: rilovanv@mail.ru

\section{Research Article \\ Volume 2 Issue 3}

Received Date: August 03, 2018

Published Date: September 28, 2018

\begin{abstract}
Active physical exercises are associated with high body mineral demand that can cause mineral disbalances with diverse negative health outcomes. The purpose of this study is to examine the impact of sport-related factors on mineral composition in young athletes. Saliva and hair samples were chosen for the analysis as reflecting immediate and more permanent mineral status, respectively. The samples were analyzed by spectral methods with inductively coupled plasma for eight essential minerals: calcium (Ca), chromium ( $\mathrm{Cr}$ ), iron (Fe), potassium (K), magnesium (Mg), selenium (Se), and zinc (Zn). The results from athletes were compared to ones from the control group of adolescent non-athletes. Different minerals demonstrated sampling specific distribution. Sport type specificity of mineral content was found. These findings can help in the process of mineral status data standardization and in training process to correct the sport-associated mineral disbalances.
\end{abstract}

Keywords: Young Athletes; Hair and Saliva Microminerals; Physical Exercises

\section{Introduction}

The optimal time to begin specialization in a particular sport remains debatable. Nevertheless the number of young people starting their intensive practice in certain sports grows. The number of specialized organizations preparing young athletes for professional sport also grows world-wide. In China and Eastern European countries these organizations have existed for decades $[1,2]$. The recent programs on genetic testing for sport talent identification additionally attract young people to hard training to become elite athletes [3]. The physical growth of children and adolescents results in the high demand for vitally important macro- and microminerals (trace minerals). Thus, young athletes are under double pressure because besides the mentioned growth-related need, intense physical exercises may increase the minerals losses and disbalances [4-6]. Underestimation of these factors can bring to the known negative immune systems outcomes that can be associated with both deficit and over-supplementation of micronutrients [7]. An adequate control and nutritional regimes should be developed to follow and maintain the optimal mineral status of young athletes.

To study the impact of intense sport activity on adolescent mineral composition, saliva and hair samples from 12-17 years old athletes and non-athletes living in the same geographical region of Kazan city, Russia, were analyzed by spectral methods with inductively coupled 


\section{Journal of Orthopedics \& Bone Disorders}

plasma (ICP). Saliva and hair samples were chosen to analyze immediate and long-term mineral status, respectively. The results of this study demonstrate that different minerals have sport- and sampling-specific patterns of distribution in saliva and hair samples. The found sport dependent specificities in the concentration of minerals provide the basis for adequate control and correction of sport-induced mineral disbalances in young athletes.

The general lack of mineral measurements in different geographical regions, type of studied samples, age of subjects, etc. remains a problem for the correct interpretation of body mineral data $[8,9]$. Thus, this study describing the situation in the Volga region of central Russia has a certain methodological importance as well.

\section{Materials and Methods}

\section{Subjects}

The participants were 95 children, aged from 12 to 17 years residing in the city of Kazan, Russia. All individuals were reported as healthy without any psychiatric, medical disorders or developmental delay. The samples from young athletes were divided according to the specific sport types: field hockey and fencing. A control group included 28age- and sex-matched teenagers with reported sport activity less than four hours per week. The girls from the fencing group were significantly $(\mathrm{p}<0,05)$ taller and heavier compare to other groups. The data on the groups are summarized in Table 1.

\begin{tabular}{|c|c|c|c|c|c|c|c|}
\hline Groups & Gender & Number & $\begin{array}{c}\text { Sport experience } \\
\text { (years) }\end{array}$ & Age (years) & Height (cM) & Body mass (kg) & ВMI (кг/см2) \\
\hline \multirow{2}{*}{ Control } & Males & 20 & - & $14,4 \pm 0,3$ & $158,6 \pm 1,4$ & $52,5 \pm 1,5$ & $20,78 \pm 0,3$ \\
\cline { 2 - 8 } & Females & 8 & - & $14,75 \pm 0,61$ & $165,5 \pm 0,6$ & $57,18 \pm 3,66$ & $20,55 \pm 0,79$ \\
\hline \multirow{2}{*}{ Field hockey } & Males & 18 & $6,25 \pm 0,59$ & $15,6 \pm 0,2$ & $163,9 \pm 1,7$ & $56,4 \pm 1,4$ & $20,97 \pm 0,4$ \\
\cline { 2 - 8 } & Females & 29 & $7 \pm 0,41$ & $15,78 \pm 0,2$ & $175,13 \pm 1,17^{*}$ & $67,87 \pm 2,51 *$ & $22,04 \pm 0,69$ \\
\hline \multirow{2}{*}{ Fencing } & Males & 10 & $6,4 \pm 0,56$ & $14,8 \pm 0,5$ & $162,8 \pm 1,7$ & $56,0 \pm 1,6$ & $21,0 \pm 0,4$ \\
\cline { 2 - 8 } & Females & 10 & $6,4 \pm 0,47$ & $14,5 \pm 0,58$ & $167,55 \pm 3,27$ & $58,09 \pm 3,07$ & $20,61 \pm 0,77$ \\
\hline
\end{tabular}

Where: BMI is Body Mass Index; * - significance of differences $p<0,05$

Table 1: Characteristics of the study participants groups.

\section{Sampling}

Hair samples were collected close to the scalp from the occipital region in a sufficient quantity for analysis. Before cleavage, the hair samples were washed first in acetone and then three times with deionized water and dried. The hair samples of $100 \mathrm{mg}$ were placed into teflon test tubes of a microwave digestion system in $1 \mathrm{ml}$ of the concentrated nitric acid. The test tubes were capped and placed into the microwave digestion system on $115^{\circ} \mathrm{C}$ for 1 hour. After digestion, all the samples were taken from the microwave oven and cooled to room temperature. The digested samples were put into $50 \mathrm{mlpolypropylene} \mathrm{tubes}$ and brought to the final volume $(10 \mathrm{ml})$ with ultrapure water («MilliPore», Merc).

To make saliva samples more reflecting the sportassociated conditions, the sampling from athletes took place at the training centers. The saliva samples $(0,5 \mathrm{ml}$ volume) were added to $1 \mathrm{ml}$ of the concentrated nitric acid. The following procedures are identical to ones for hair samples. To dissolve the samples certified free metalfree nitric acid (Merc) was used.

\section{Analytical Methods}

Mineral concentrations were assessed using the inductively coupled plasma methods that have recently been validated for its applicability to the analysis of young people exposure to minerals [10]. The methods selection was based on the approach described previously by Harrington et al.: inductively-coupled plasma mass spectrometry (ICP-MS) was used for the quantification of elements having very low concentration range in samples whereas inductively coupled plasma optical emission spectrometry (ICP-OES) was used for quantification of more ubiquitous elements [9]. Thus, the ICP-MS method was used for quantification of $\mathrm{Se}, \mathrm{Cr}$ and $\mathrm{Zn}$ and the ICP$\mathrm{OES}$ one for $\mathrm{Mg}, \mathrm{K}, \mathrm{Ca}$, Fe quantification, respectively. The resulting solutions were analyzed by a quadrupole mass spectrometer with inductively coupled plasma («Elan9000», PerkinElmer). The «Optima 2000 DV» (PerkinElmer) was used as an optical emission spectrometer with inductively coupled plasma. To calibrate the instruments; multi-element standard solutions were (PerkinElmer). The blank solution results were taken into account in the analysis of the samples. To 


\section{Journal of Orthopedics \& Bone Disorders}

account for the effect of the acid, acidic blank solution was added.

\section{Statistics}

Using SPSS Statistics 14.0K (IBM, Chicago, USA), descriptive statistics were carried for all variables. The data were expressed as mean (M) and Standard Error Means (SEM, m).

\section{Results and Discussion}

Although the growing involvement of young people in recreational sport is a very positive trend for public health, the number of young athletes in healththreatening competitive and semi-professional sport grows. The latter requires certain measures for the identification and correction of the competitive sportassociated disbalances including the body minerals ones. In the present study we compared mineral status of young athletes with the one of matched non-athletes.

Sport disciplines different in speed, power, endurance, and environment have different sport-specific mineral losses [11-13]. We studied two groups of athletes representing field hockey and fencing, two sport quite different in the trained skills. All subjects were from the same region of Kazan city, Russia, which allowed us to avoid the biases, related to region-specific differences in food and water minerals.

In the present study hair and saliva samples were taken to study immediate and long-term mineral status, respectively. Samples were analyzed by mass spectrometry methods that have recently been validated for its applicability to the analysis of body mineral status.

The increased concentrations of $\mathrm{K}$ and Se were found for both athlete groups in hair and saliva specimen (Table 2 ). These results are in line with previously described ones that students, involved in high physical activities, have an increased Se level [14]. However, in our study Fe demonstrated decreased concentration in hair samples, which can be related to both geographical differences and to the age of studies groups (Table 2A) [14]. Basing on the increased hair $\mathrm{Zn}$ and Fe concentrations, we can assume a generally good nutritional status for the studied young athletes [15]. The Fe concentration in athlete saliva was similar to control.

\begin{tabular}{|c|c|c|c|}
\hline Mineral & Control & Fieldhockey & Fencing \\
\hline $\mathrm{Ca}$ & $813,9 \pm 102,33$ & $1056 \pm 62,66$ & $652 \pm 49,82$ \\
\hline $\mathrm{Cr}$ & $1,319 \pm 0,36$ & $0,22 \pm 0,063^{*}$ & $0,608 \pm 0,079$ \\
\hline $\mathrm{Fe}$ & $35,58 \pm 3,69$ & $23,23 \pm 3,62^{*}$ & $16,73 \pm 2,08^{*}$ \\
\hline $\mathrm{K}$ & $30,27 \pm 6,25$ & $98,87 \pm 14,41^{*}$ & $115,56 \pm 20,23^{*}$ \\
\hline $\mathrm{Mg}$ & $68,137 \pm 7,67$ & $95,36 \pm 8,29^{*}$ & $63,89 \pm 6,3$ \\
\hline $\mathrm{Se}$ & $0,397 \pm 0,0266$ & $0,47 \pm 0,012^{*}$ & $0,53 \pm 0,0187^{*}$ \\
\hline $\mathrm{Zn}$ & $83,28 \pm 5,79$ & $183,75 \pm 17,91^{*}$ & $140,97 \pm 12,09^{*}$ \\
\hline
\end{tabular}

Where: * reflect the level of difference significance to control group less than 0,05 .

Table 2A: Micromineral contents in hair of athletes and control groups $(\mathrm{mg} / \mathrm{kg})$.

Sampling-dependent differences were found for several minerals. Potassium levels in athletes were lower in saliva and higher in hair in comparison to the ones of control group. Chromium levels demonstrated rather opposite to potassium distribution in saliva and hair. These found sample-specific differences confirm the data of other authors the minerals can have samplingdependent specificity [16]. Altogether these athlete specific features of minerals distribution seem to reflect body adaptation to the general competitive sport conditions: psychological stresses, scheduled time regime etc.

Nevertheless, sport specific features of mineral distribution were identified in both athletic groups.
Fencing and field hockey belong to two different sport types. Fencing is more specific to the development of very precise technical skills whereas field hockey includes very strong endurance component. This can explain why the mineral concentrations of fencers looked more similar to ones of the control group. Small wonder that hockey players, for whom endurance is critical, had the increased, compare to control and fencing groups, levels of saliva and hair magnesium, required for normal muscular function, especially the heart. The hair content of chromium was decreased in hockey players compare to control, which can reflect the long-term status of glucose metabolism (Table 2B). 


\section{Journal of Orthopedics \& Bone Disorders}

\begin{tabular}{|c|c|c|c|}
\hline Mineral & Control & Fieldhockey & Fencing \\
\hline $\mathrm{Ca}$ & $44,45 \pm 2,32$ & $40,64 \pm 1,69$ & $25,23 \pm 1,98^{*}$ \\
\hline $\mathrm{Cr}$ & $0,003 \pm 0,0002$ & $0,25 \pm 0,0018^{* *}$ & $0,013 \pm 0,0007^{*}$ \\
\hline $\mathrm{Fe}$ & $0,046 \pm 0,01$ & $0,032 \pm 0,001$ & $0,0312 \pm 0,0049$ \\
\hline $\mathrm{K}$ & $1456,82 \pm 78,98$ & $782,81 \pm 28,07^{*}$ & $401,43 \pm 50^{*}$ \\
\hline $\mathrm{Mg}$ & $3,87 \pm 0,3$ & $6,53 \pm 0,51^{*}$ & $2,67 \pm 0,48$ \\
\hline $\mathrm{Se}$ & $0,0064 \pm 0,0003$ & $0,012 \pm 0,0011^{*}$ & $0,015 \pm 0,00032^{*}$ \\
\hline $\mathrm{Zn}$ & $0,032 \pm 0,0043$ & $0,13 \pm 0,019^{*}$ & $0,02 \pm 0,007$ \\
\hline
\end{tabular}

Where: * reflect the level of difference significance to control group less than 0,05 .

Table 2B: Micromineral contents in saliva of athletes and control groups (mg/l).

Field hockey players demonstrated the increased compare to control levels of magnesium in both saliva and hair samples that were absent in the fencing group. Together with the increased hair potassium level these findings make the field hockey group similar to patients with acute ischemic stroke [17]. Hockey players spend a lot of play time bent at the waist and leaning over their sticks. This forward head posture causes chronic shortening of the suboccipital muscles lead to ischemia and trigger points that can be reflected in hair mineral content. Of interest, neck blows is associated with sportspecific death among amateur hockey players [18].

\section{Conclusions}

In conclusion, we have found that mineral content results are specific for the chosen hair and saliva samples. These findings should be taken in account for standardization and reference values of mineral measurement. This study also suggests that there are clear specificities, associated with the long-term and high level of physical exercises. Moreover, sport type specialization in young athletes causes specific for the chosen sport mineral disbalances. These findings can be used for the further identification and correction of mineral disbalances that can cause the pathologies associated with intensive specific sport activities in young athletes.

\section{Acknowledgments}

\section{Compliance with Ethical Standards}

Sample collection procedures followed the Helsinki Declaration guidelines regarding informed consent of human volunteers or their representatives (parents in our case).

\section{Conflict of Interest}

Authors declare no conflicts of interest.

\section{References}

1. Goncalves CE, Rama LM, Figueiredo AB (2012) Talent identification and specialization in sport: an overview of some unanswered questions. Int J Sports Physiol Perform 7(4): 390-393.

2. Malina RM (2010) Early sport specialization: roots, effectiveness, risks. Curr Sports Med Rep 9(6): 364371.

3. Roth SM (2012) Critical overview of applications of genetic testing in sport talent identification. Recent Pat DNA Gene Seq 6(3): 247-255.

4. Montain SJ, Cheuvront SN, Lukaski HC (2007) Sweat mineral-element responses during $7 \mathrm{~h}$ of exerciseheat stress. Int J Sport Nutr Exerc Metab 17(6): 574582.

5. Speich M, Pineau A, Ballereau F (2001) Minerals, trace elements and related biological variables in athletes and during physical activity. Clin Chim Acta 312(1-2): 1-11.

6. Williams MH (2005) Dietary supplements and sports performance: minerals. J Int Soc Sports Nutr 2(1): 4349.

7. Gleeson M, Bishop NC (2000) Elite athlete immunology: importance of nutrition. Int J Sports Med 21 (S1): S44-S50.

8. Harrington JM, Young DJ, Essader AS, Sumner SJ, Levine KE (2014) Analysis of human serum and whole blood for mineral content by ICP-MS and ICPOES: development of a mineralomics method. Biol Trace Elem Res 160(1): 132-142

9. Mikulewicz M, Chojnacka K, Gedrange T, Gorecki H (2013) Reference values of elements in human hair: a 


\section{Journal of Orthopedics \& Bone Disorders}

systematic review. Environ Toxicol Pharmacol 36(3): 1077-1086.

10. Harrington JM, Young DJ, Fry RC, Weber FX, Sumner SS, et al. (2015) Validation of a Metallomics Analysis of Placenta Tissue by Inductively-Coupled Plasma Mass Spectrometry. Biol Trace Elem Res 169(2): 164173.

11. Castronovo AM, Conforto S, Schmid M, Bibbo D, D'Alessio $T$ (2013) How to assess performance in cycling: the multivariate nature of influencing factors and related indicators. Front Physiol 4: 116.

12. Resende NM, de Magalhaes Neto AM, Bachini F, de Castro LE, Bassini A, et al. (2011) Metabolic changes during a field experiment in a world-class windsurfing athlete: a trial with multivariate analyses. OMICS 15(10): 695-704.

13. Robertson S, Benardot D, Mountjoy M (2014) Nutritional recommendations for synchronized swimming. Int J Sport Nutr Exerc Metab 24(4): 404413.
14. Zaitseva IP, Skalny AA, Tinkov AA, Berezkina ES, Grabeklis AR, et al. (2015) The influence of physical activity on hair toxic and essential trace element content in male and female students. Biol Trace Elem Res 163(1-2): 58-66.

15. Weber CW, Nelson GW, Vasquez de Vaquera M, Pearson PB (1990) Trace elements in the hair of healthy and malnourished children. J Trop Pediatr 36(5): 230-234.

16. Blaurock-Busch E, Amin OR, Rabah T (2011) Heavy metals and trace elements in hair and urine of a sample of arab children with autistic spectrum disorder. Maedica (Buchar) 6(4): 247-257.

17. Karaszewski B, Kozera G, Dorosz A, Lukasiak J, Szczyrba S, et al. (2007) High magnesium or potassium hair accumulation is not associated with ischemic stroke risk reduction: a pilot study. Clin Neurol Neurosurg 109(8): 676-679.

18. Maron BJ, Poliac LC, Ashare AB, Hall WA (2003) Sudden death due to neck blows among amateur hockey players. JAMA 290(5): 599-601. 